\title{
FORMATION OF TECHNICAL AND TECHNOLOGICAL COMPETENCIES IN ELECTRICAL ENGINEERING AND ELECTRONICS IN TRAINING TEACHERS
}

\author{
Alexander Korets \\ Ph.D. in Pedagogical Sciences, National Pedagogical Dragomanov University, Ukraine \\ e-mail: m.s.korets@npu.edu.ua,orcid.org/0000-0001-5791-803X \\ Andry Didyk \\ Postgraduate Student, National Pedagogical Dragomanov University, Ukraine \\ e-mail: didyka@ukr.net, orcid.org/0000-0003-0968-1060
}

\section{Summary}

The article analyzes the knowledge of electrical engineering and electronics in the context of the competency approach in terms of remote mode and personal routine of the student. The ability to apply the acquired cognitive experience in the created experimental situations is revealed. It is shown that the monitoring determined the ability of students to build their own knowledge system with the involvement of the latest information technologies. The expediency of using innovative methods and technologies at different stages of forming the quality of training of future specialists in electrical engineering and electronics in the conditions of distance learning is determined. The main types, functions and modes of using computer support in the distance learning process are presented. Emphasis is placed on the need to make the right correction, to develop individual approaches and programs, to take into account psychological and pedagogical indicators and criteria for the effectiveness of distance learning. It is noted that the use of computers allows you to find the best ways to solve problems, while improving the learning process. The requirements of the experiment, the unity of experimental and theoretical methods of cognition are analyzed. The basic ways of motivation of activity of students and features of formation and development of competence-worldview professional qualities of the future teacher of technological educational branch are opened. It is determined that the process of professional training should solve the problem of forming a competent specialist who is fluent in modern innovative technologies and ready for constant professional growth, social and professional mobility.

Keywords: monitoring, distance learning, technical and technological competence, virtual environment, cloud technologies.

DOI https://doi.org/10.23856/4309

\section{Introduction}

In the extreme conditions of today in Ukraine, issues related to the formation of technical and technological competencies in electrical engineering and electronics have become extremely important. For teachers of vocational training, the problem of their professional training of students in this discipline occupies one of the leading places in the educational process. Distance learning has made its adjustments in the educational information space, encouraging students to better acquire knowledge. And this is natural. After all, the labor market is making more and more demanding requests to future specialists - masters of their craft, erudite, highly 
qualified, capable of introducing innovative technologies into their work. And this significantly affects the social order. Tireless research and studies in the field of electrical engineering and electronics in any case lead to new ideas, to a new vision of solving the problem in the field of education.

The aim of research is to study the problem of formation of technical and technological competencies. By monitoring to investigate the level of formation of electrical engineering and electronics in future teachers of vocational education in distance learning.

\section{Presentation main research material}

The information influx of new educational technologies has led to the revision of the methods of teaching electrical engineering and electronics in technical educational institutions and in the system of training teachers in vocational training in particular. In the process of studying electrical engineering and electronics, this went unnoticed and became especially relevant after Ukraine's accession to the Bologna Agreement, where the main emphasis is on independent work. All this highlighted a number of issues regarding the revision of the structure and content of electrical engineering and electronics in the context of distance learning.

The use of modern computer-aided learning technologies (CTT) allows a deeper understanding of the processes that take place in complex electrical systems as a whole. Currently, technological education of students should be focused on the study of new production processes, modernization of production relations, which include information and communication and other modernized means of production (automation, robotics, circuitry, laser technology, etc.) (Osadchy, 2012).

Creating something original that has not yet been tested in the teaching of any discipline is now problematic. Cloud technologies offer such a variety of methods that it is enough to demand everything wisely and wisely. You need, as always, a persistent search. Therefore, each teacher must choose for themselves those methods that give the maximum result for the development of creative personality.

The level of education should provide students with the ability in the future to create and implement innovative technologies, the theoretical basis of which probably has not yet been developed during their studies at the university. Information technology has a great impact on young people. It forms a new style of information processing, a new style of thinking - "mosaic-clip" (ie not book images, but video clips of the global computer network), and this requires updating the didactic system, developing adaptive methods and learning technologies.

The phenomenon of "clip thinking" has been talked about recently. This problem is considered in more detail in the works of leading foreign sociologists, such as the American futurist E. Toffler. In his monograph "Third Wave" he writes that "... instead of obtaining spatial" bands "of ideas, collected and systematized, which relate to each other, we are increasingly crammed with short modular flashes of information - advertising, teams, theories, snippets of news, somehow circumcised, truncated, which do not fit into our former mental concepts" (Toffler, 2010).

Prominent British scientist James Martin, who predicted the advent of the Internet, conventionally divided people into two types:

- "people-books" (receive information from books, have figurative, logical thinking, steady attention, ability to analyze). This is the older generation (educators, teachers); 
- "screen people" (receive information from cyberspace, have mosaic-clip thinking, perceive the world through the prism of "pictures", TV and video images). These are young people, students, pupils (Martin, 2012).

With this thinking, the student seems to live in virtual reality, which is filled with a mosaic of disparate, unrelated facts, parts, fragments of information. He somehow imperceptibly gets used to this kaleidoscope: exciting music, chatting, playing online games, dating and more.

Today, ICT provides the opportunity to conduct distance lectures, seminars, demonstration of video and animation materials on various educational servers, work on educational telecommunications projects, the organization of distance competitions in electrical engineering and electronics, etc. At the same time, distance learning servers create reliable conditions for interactive communication with students via the Internet, including in real time.

The introduction of innovative technologies has significantly improved the quality of the educational process, has a positive impact on the development of independent and individual work of students. Given the unforeseen circumstances, distance education has been widely used. Practically, it is created on virtual learning tools. Its importance is difficult to overestimate, especially for those who have undergone inclusive schooling.

Remote technologies are educational technologies that are created in a virtual space for interaction "student - teacher", "teacher - student" online. For example, an online lab (virtual $\mathrm{lab}$ ) is an important segment of the educational environment through which a "remote experiment" can be performed.

Distance education is unique, because in its essence it combines elements of full-time, part-time, distance and evening learning based on information technology and multimedia systems. It is characterized by flexibility, modularity, cost-effectiveness, maximum use of information technology.

Distance education, like the traditional learning process, uses the following didactic teaching methods adapted for cyberspace: informational, virtual, reproductive, problem-based, research, heuristic, design, individual, gamification (game elements). Therefore, virtually performed experiments and experiments in artificial laboratory conditions complement the fullscale laboratory work. This is an example of empirical knowledge of objective reality, but at the same time an effective method of scientific knowledge. The effectiveness of the virtual application of research and experimental work is undeniable. This indicates the positive dynamics of the process of training future teachers of vocational education in electrical engineering and electronics, which is implemented on the integration of theoretical and practical experience and virtual-experimental work. First of all, this is facilitated by a well-constructed learning space on the Internet and around the student.

If distance education is considered in terms of competence, then learning is in line with the interaction of aspects: educational, professional and social. However, this form has some disadvantages: the service server can be underloaded or overloaded depending on the number of listeners. An innovative solution to this was the use of cloud technologies (Internet technologies). Cloud technology is a model for providing exciting and convenient network access at any time. You can easily find relevant information, share it with other users from anywhere in cyberspace.

Cloud Computing is a system that allows remote processing and storage of data. Cloud servers provide unlimited opportunities to build a variety of learning situations in which students gain experience. They are indispensable in the work of the teacher. The use of cloud technologies is increasing rapidly. This makes knowledge even more accessible. Now you can get the information you need not only indoors but also outdoors. 
Thus, cloud technologies and the virtual educational space created on their basis are an innovative alternative to the traditional educational process. The cloud network opens up incredible opportunities for those who are learning to communicate with a wide range of participants, regardless of their location (Bikov, 2010).

Cloud technologies for distance e-learning provide its high level: increase the efficiency of students' learning activities, increase interest in learning the discipline, the development of logical thinking, memory, save time. Creating blogs, the use of art scribing (the method of visualizing complex text is simple and accessible by sketching images simply while receiving information) promotes better learning of complex material. The teacher's inclination to virtualization, to involve cloud servers in their activities inspires great hope that online technologies will continue to create positive conditions for student self-realization, development of his creative abilities, leadership skills, worldviews.

The current situation under duress has reduced classroom activities, but instead has incredibly increased access to online information. And this promotes active cooperation of students with teachers and with each other, as evidenced by the results of monitoring. There is complete confidence that in the future, virtual laboratories will operate at full capacity.

Monitoring (a system of constant monitoring of phenomena and processes in education and society) is one of the powerful levers for increasing the quality of professional training of students. It provides a direct answer to the question "Why such a level of knowledge and how to improve its effectiveness?".

Monitoring research in electrical engineering and electronics, which aimed to obtain reliable information about the state of acquisition of theoretical knowledge and practical skills in the virtual environment, was conducted on the following parameters: cognitive aspect (auditory and visual memory, attention, professional thinking, intelligence); creative abilities (talent, skill); personal qualities (motivation to choose a profession, incentive to study, sociability, honesty, diligence, interests, views, beliefs).

The main content of monitoring was to obtain accurate data on the implementation of effective independent learning activities using ICT in distance education, which became the technological basis of the system of knowledge in electrical engineering and electronics. This made it possible to accumulate and process a huge amount of various information, which proved to be a solid basis for making important management decisions.

As a result, it can be argued that the formation of professional skills and abilities of the future specialist depends not only on intellectual abilities, but also on personal attitude to professional activity and awareness of its significance, social value. In essence, self-knowledge cannot stand still: the future employee must adequately perceive himself and others, think critically and creatively, manage stress and successfully solve problems. It is monitoring that allows us to delve into the essence of the educational problem, the identification of which is the first step towards overcoming it. For the purpose of independent search of the necessary information in a network to replace classroom employment with a traditional technique it is expedient:

- create a site of virtual access to lectures online;

- develop and download tasks for individual training, which will form the professional competence of future professionals;

- to introduce blended (hybrid) learning technology, which allows to create virtual groups that will be able to use cloud technologies.

Monitoring confirmed four levels of experience in the process of teaching a student in a particular subject, differentiated as follows (Atamanchuk, 2006): 


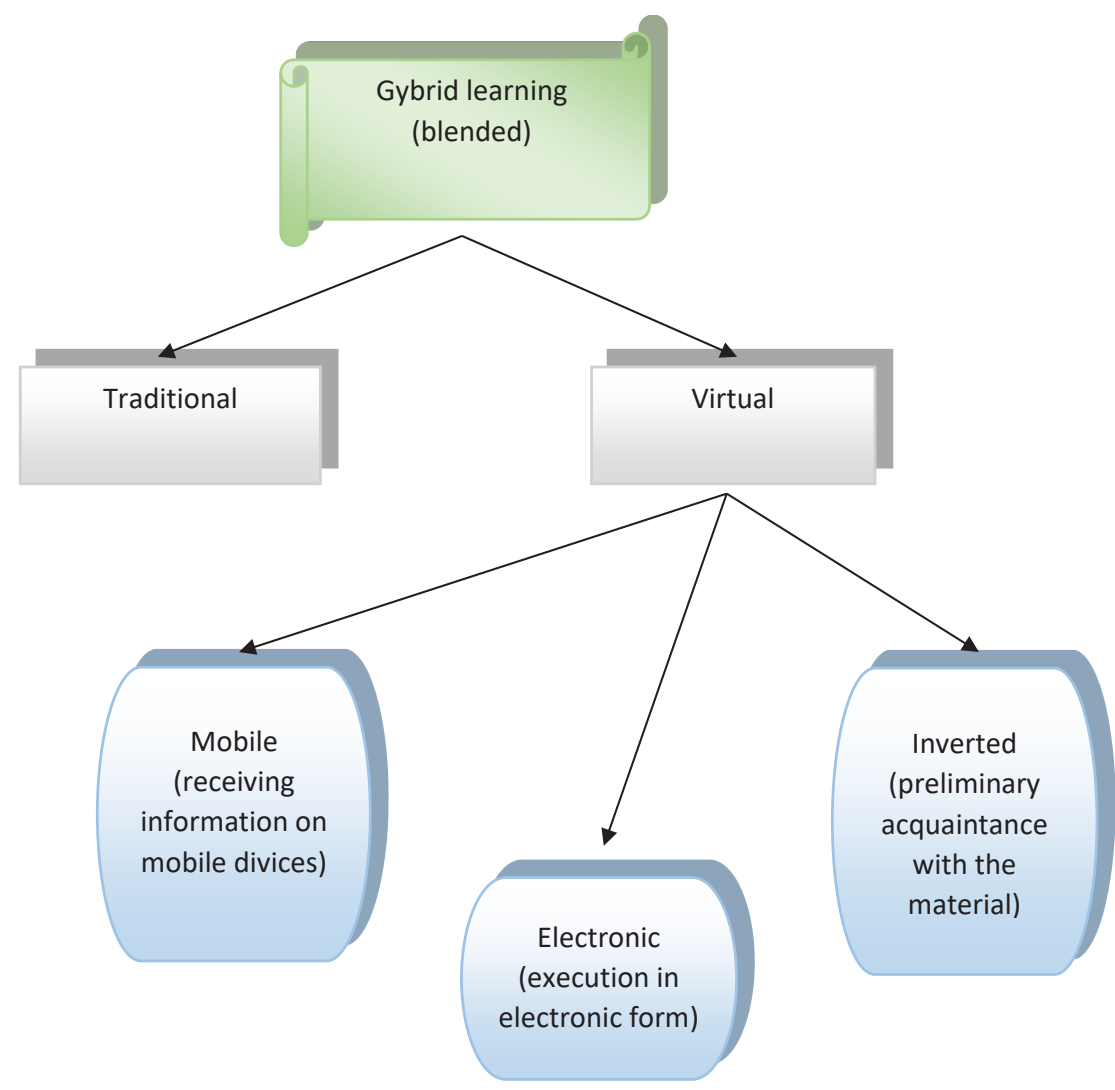

Fig. 1. Types of learning in the information environment

The first level. If the task contains the purpose, situation, actions concerning its decision, and the student should draw a conclusion on conformity of all components in structure of the task, it is activity on recognition (the student only distinguishes object or actions from their analogues, showing superficial acquaintance with ob 'object or process of cognition, with their external characteristics).

The second level. If there is a goal and a situation, and the student applies pre-learned actions to solve it, then it is a reproductive activity. He is able not only to choose from a number of features a particular object or phenomenon, but also to understand the meaning of the concept, to reproduce the meaning.

The third level. If there is a goal in the task, but the situation in which this goal can be solved is not completely clear, then the student must find out the situation and take appropriate action. This is a heuristic method. The heuristic action does not occur according to this algorithm, but according to the created or redesigned one.

The fourth level. If the task has only the purpose of activity, and the situation needs to be found, and actions are directed on achievement of the purpose, it is a productive creative action. In the process of such creativity the necessary information is received.

To assess the performance of each task V. P. Bespalko proposes to determine the number of significant operations leading to the solution of the test (p). Comparing the student's answer with the standard (p) by the number of correctly performed test operations (a) makes it 
possible to determine the coefficient of assimilation $\left(K_{j}\right)$, which is calculated by the formula (Bespalko, 1989):

$$
\mathrm{K}_{\mathrm{j}}=\frac{\mathrm{a}}{\mathrm{p}}
$$

Determining the number of significant transactions, including for the tasks of the second, third and fourth levels it turns out to be somewhat problematic for some reasons:

- subjective statement of the fact of significance of this or that operation (the number of operations performed in the tests will change, and this will affect the calculated coefficient of assimilation in one direction or another);

- the process of selecting tests and calculating its results is complicated;

- the basis of operations may be different (in fact, the wrong solution of the least significant of the operations is equated either to incorrect execution of the task, in one case, or to incomplete or inaccurate, in another case).

You can use a scale from 0 to 2 points to evaluate each of the tasks of the experiment. The second and third level of mastering: 2 points - for correct and final performance; 1 point for correct but partial, sometimes for inaccurate performance; 0 points - for erroneous performance of the task. For the tasks of the first level of mastering the scale of two grades: 1 point correct; 0 points - incorrect.

The coefficient of assimilation introduced by V. Bespalkom, adapts to certain conditions and is calculated for a single level of learning according to the following formula:

$$
\mathrm{K}_{\mathrm{i}}=\frac{\mathrm{N}_{\mathrm{i}}}{\mathrm{L}_{\mathrm{i}}}
$$

where $K_{i}$ is the coefficient of the $\mathrm{i}-$ th level of assimilation;

$N_{i}$ - the number of points received by the student for completing the tasks of the i-th level of mastery; of mastery.

$L_{i}$ - the maximum number of points that can be obtained for the tasks of the i-th level

Table 1 and Table 2 show a comparison of the coefficients of knowledge acquisition in the control and experimental groups in the process of studying the course "Electrical Engineering" and "Electronics".

Table 1

Distribution of coefficients of knowledge acquisition in electrical engineering

\begin{tabular}{|l|l|c|c|c|c|}
\hline \multirow{2}{*}{ Type control } & \multirow{2}{*}{ Group } & \multicolumn{3}{|c|}{ Levels assimilation } & \multirow{2}{*}{$\begin{array}{c}\text { Generalized Coefficient } \\
\text { of knowledge acqusition }\end{array}$} \\
\cline { 3 - 5 } & & I level & II level & III level & 0,62 \\
\hline molding & & $\mathbf{0 , 9 2}$ & $\mathbf{0 , 7 5}$ & $\mathbf{0 , 5 1}$ & 0,52 \\
\hline \multirow{2}{*}{ ascertaining } & control & 0,83 & $\mathbf{0 , 6 1}$ & $\mathbf{0 , 4 2}$ & 0,56 \\
\cline { 2 - 5 } & experimental & 0,88 & $\mathbf{0 , 6 5}$ & $\mathbf{0 , 4 6}$ & 0,59 \\
\hline \multirow{2}{*}{ final } & control & 0,80 & $\mathbf{0 , 6 4}$ & $\mathbf{0 , 5 3}$ & $\mathbf{0 , 6 3}$ \\
\cline { 2 - 5 } & experimental & 0,78 & $\mathbf{0 , 7 3}$ & $\mathbf{0 , 6 2}$ & 0,67 \\
\hline
\end{tabular}

To study the formation of technical and technological competence, we conducted an experiment with the participation of 232 students 2, 3, 4, courses, studying at the bachelor's degree in "Professional Education (by specialization)" in various higher education institutions. At the same time, they were tested, their current and resulting success in the studied discipline 
"Electrical Engineering" and "Electronics" was taken into account and the generalized coefficient of formation of technical and technological competence was determined. They studied in the control group according to the classical program and the experimental group according to the experimental program.

Table 2

Distribution of coefficients of knowledge acquisition in electronics

\begin{tabular}{|l|l|c|c|c|c|}
\hline \multirow{2}{*}{ Type control } & \multirow{2}{*}{ Group } & \multicolumn{3}{c|}{ Levels assimilation } & \multirow{2}{*}{$\begin{array}{c}\text { Generalized Coefficient } \\
\text { of knowledge acqusition }\end{array}$} \\
\cline { 3 - 5 } & & I level & II level & III level & 0,61 \\
\hline molding & & $\mathbf{0 , 9 2}$ & $\mathbf{0 , 7 3}$ & $\mathbf{0 , 5 0}$ & 0,50 \\
\hline \multirow{2}{*}{ ascertaining } & control & 0,82 & $\mathbf{0 , 5 9}$ & $\mathbf{0 , 4 1}$ & 0,55 \\
\cline { 2 - 5 } & experimental & 0,88 & $\mathbf{0 , 6 3}$ & $\mathbf{0 , 4 5}$ & 0,57 \\
\hline \multirow{2}{*}{ final } & control & 0,79 & $\mathbf{0 , 6 2}$ & $\mathbf{0 , 5 2}$ & 0,66 \\
\cline { 2 - 5 } & experimental & 0,76 & $\mathbf{0 , 7 2}$ & $\mathbf{0 , 6 1}$ & \\
\hline
\end{tabular}

From table 1 and table 2 it follows that in the experimental groups the generalized coefficient of knowledge on the results of the final control is 0.67 (compared with 0.59 in the control groups) in electrical engineering and 0.66 (compared with 0.57 in control groups) in electronics. This is reflected in the increase in the coefficient of assimilation of the II and III levels in the experimental groups in comparison with the control groups.

\section{Conclusions}

Thus, the ways of formation of technical and technological competencies by future teachers of professional training in the process of studying electrical engineering and electronics are outlined. The monitoring of the formation showed the results of the experiment. The structure of the information-learning environment allows each student to determine their own trajectory in the acquisition of theoretical and practical knowledge. The use of distance learning methods has raised the importance of individual abilities in acquiring knowledge.

\section{References}

Atamanchuk P.S. (2006) Methodical bases of organization and carrying out of educational physical experiment: Kamyanets-Podilsky: information and publishing department [in Ukrainian] Bespalko V.P (1989) Components of pedagogical technology : Moskov:Pedagogy [in Russian] Bikov V.Yu. (2011) Cloud technologies, ICT - outsourcing and new functions of ICT units of educational and scientific institutions [Information technologies in education] vol. 6, no. 144, pp. 8-23: Access mode: http://nbuv.gov.ua/UJRN/itvo_2011_(accessed 10 January 2021)

Bikov V.Yu. (2010) Technologies of cloud computing - leading information technologies of further development of informatization of the education system in Ukraine [Computer in school and family] vol. 3, no. 107, pp. 3-11.

Martin J. A turning point in the history of mankind [Electronic resource] [The world of forecast]. - Access mode: www.mirprognozov.ru/prognosis/107/150/ (accessed 16 January 2021) Osadchy V.V (2012) System of information and technological support of professional training of future teachers in the conditions of pedagogical university: Melitopol:MMD. [in Ukrainian] Toffler E. (2000) The third wave. Kiev: Universe. [in Ukrainian] 